\title{
Conditions of hazardous waste management in Poland in the context of circular economy
}

\author{
Justyna Pyssa ${ }^{1 *}$ \\ ${ }^{1}$ AGH University of Science and Technology, Faculty of Energy and Fuel, Al. Mickiewicza 30, 30-059 Cracow, Poland
}

\begin{abstract}
Along with the increase of disproportions between the rapidly growing demand for raw and essential materials and limited possibilities of obtaining them, the economy of raw and essential materials becomes the main problem of contemporary and future social and economic politics. One of the important areas of reducing this disproportion is the limitation of intensity of waste generation during production and more consistent management of accumulated waste and waste generated on a daily basis. At the same time it is a major problem of obtaining secondary raw materials and the environment protection. The selection of technology of hazardous waste disposal should take place according to the principle of circular economy. It means that the rational waste management, taking into account both ecological and economic factors, enforces the demand for maximizing the utilization of waste in all possible applications while limiting its negative impact on the environment at the same time. In the article legal acts regulating the management of hazardous waste have been analyzed. Economic and ecological criteria of the selection of technology of disposal of hazardous waste have been analyzed.
\end{abstract}

\section{Introduction}

For decades productive processes have been conducted without paying attention to the natural environment. The result of that approach was the generation of huge quantities of hazardous waste. Sacrifice of the natural environment for the benefit of economy has turned out extremely shortsighted. The problem has been noted when the natural resources have decreased significantly as a result of the expansive human activity and the devastation of natural environment has continued at an alarming rate. The first stage on the way of finding a solution was the beginning of control of the degree of contamination of the environment. That resulted in the introduction of various methods of sewage and waste treatment. Unfortunately, aftermaths of that step were not satisfactory. The next stage was about the prevention of waste generation the effect of which was the introduction of so-called clean production. The clean production meant the necessity of development of more efficient low-waste, non-waste and less energyconsuming technologies. The improved technologies were supposed to bring specific economic and environmental results after their implementation. The result was the use of even better organizational methods of prevention of waste production, creation of clean production and waste management.

New integrated approach to protecting the environment against a negative impact of industrial activity puts the emphasis predominantly on prevention, reduction and elimination of contaminants (as far as it is naturally possible) while ensuring the rational management of natural resources. This approach takes into consideration economic aspects as well. In fact, preventing, reducing and eliminating pollutants have to take into account costs and benefits. The application of procedures of this type is not an easy task due to the necessity of linking technical, economic and ecological indicators together.

\section{Structure of generation hazardous waste in the UE and Poland}

In all of the European Union (EU-27 + United Kingdom) a total of 84,21 million $\mathrm{Mg}$ of hazardous waste was generated in 2018 [1]. Dangerous waste is generated in all sectors of the economy. The structure of produced waste results from the industrial specificity of a given country. Changes in the structure of produced dangerous waste in the EU-28 and Poland in the years 2010-2018 are presented in table 1.

\footnotetext{
*Corresponding author: ipyssa@agh.edu.p1
} 
Table 1. Amounts (thousand tones) of generated hazardous waste in the years 2010-2018.

\begin{tabular}{|c|c|c|c|c|c|}
\hline \multirow{2}{*}{$\begin{array}{c}\text { Place of } \\
\text { generatio } \\
\text { n }\end{array}$} & \multicolumn{5}{|c|}{ Produced amount (thousand tones)/year } \\
\cline { 2 - 6 } & 2010 & 2012 & 2014 & 2016 & 2018 \\
\hline UE-28 & 9748 & 10072 & 9501 & 10074 & 84210 \\
& 5 & 7 & 1 & 0 & $*$ \\
\hline Poland & 1492 & 1737 & 1876 & 1917 & 2184 \\
\hline
\end{tabular}

* EU-27 + United Kingdom

Source: author's own research on the basis of [1]

In figure 1 the division of methods of proceeding with particular groups of hazardous waste produced in Poland in 2014 is listed and it takes into account numbering of groups of waste according to the catalogue of waste [2]. Waste from groups 02, 03, 04, 05 and 18 virtually all undergoes processes of disposal (D10) incineration on land, while waste from the group 07 almost all is subject to processes of recovery (R1 - use principally as a fuel or other means to generate energy and R11 - use of waste obtained from any of the operations numbered R1 to R10).

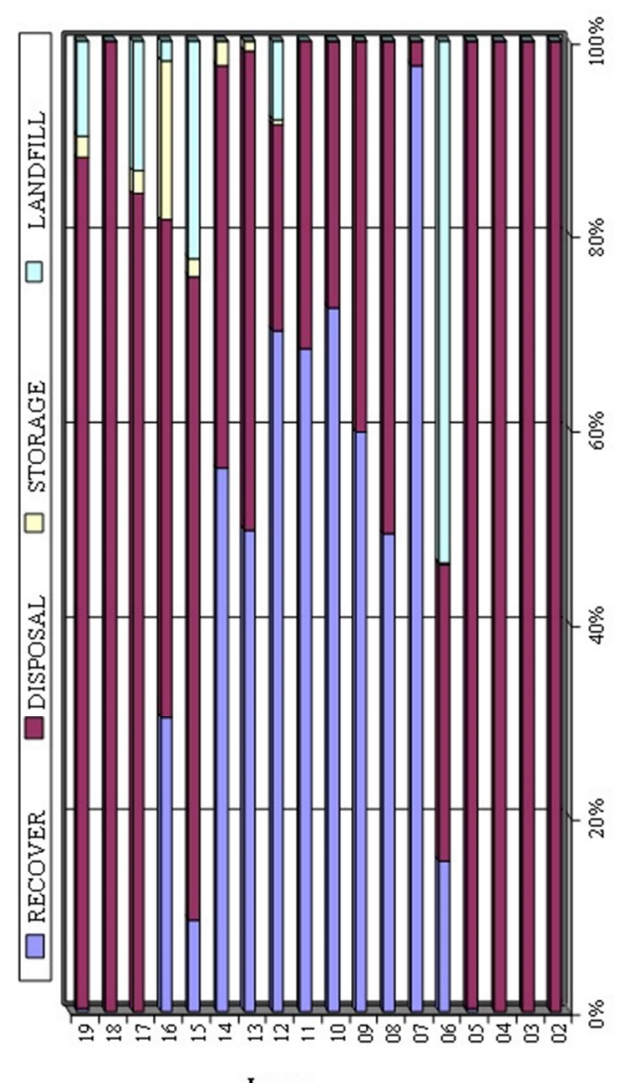

dno.p

Fig. 1 Percent share of techniques of proceeding with hazardous waste generated in Poland in 2014 in particular waste groups. Source: own research based on [3, 4]

\section{Hazardous waste management}

Before making the decision as the choice of technology of disposal of a given group of waste it is necessary to familiarize oneself with many issues of both legal and technical and economic nature. In the majority of countries legal provisions have been introduced which precisely define processes connected with sourcing, storage, transportation and technologies of treatment of given groups of waste. The knowledge in this area is provided by directives of the European Union and changes in legal provisions of the Polish law [5].

The main criterion which should be followed during the selection of technology for both recovery as well as disposal of waste is the principle of sustainable development. Under the notion of sustainable development, according to the Act of environmental law [6] article 3 point 50, one understands such economic and social development in which a process of integrating political, social and economic activities occurs while preserving the environmental balance and duration of basic environmental processes in order to guarantee all possibilities of catering essential needs of particular communities and citizens of both the contemporary generation and future generations. It means that the rational waste management (i.e. such which considers both ecological and economic factors) enforces the need for maximizing the use of waste in all possible applications while limiting its negative influence on the environment at the same time.

\subsection{Environmental conditions}

Generation of waste and its management or disposal is closely connected with the use of environment and therefore with the influence onto environment. For that reason the natural thing is assessing the impact of waste as well as methods of waste management on the surrounding in a broader sense. The evaluation of influence on the environment is a procedure enabling the identification of all probable impacts of a given venture and alternative solutions on the natural, social and cultural environment. The procedure also allows to recognize applicable actions for eliminating and minimizing negative effects and takes into consideration the contribution of society both in the process of identification of hazards and making decisions.

All created plans of waste management must include forecasts of the environmental impact, so studies on effects of introduction and discontinuing particular activities related with the waste management.

In the work [7] a detailed analysis of the influence of particular installations onto the natural environment as well as economic analysis of taken actions related with the waste management is placed.

The analysis of the impact of particular waste recovery and disposal installations on the natural environment is presented in figure 2. The following factors have been analyzed:

- GWP (Global Warming Potential) - expressed by the quantity $(\mathrm{kg})$ of generated conversion $\mathrm{CO}_{2}$ to a kilogram of transformed waste $\left[\mathrm{kg}\right.$ of $\mathrm{CO}_{2 \text {-eq }} / \mathrm{kg}$ of waste],

- AP (Acidification Potential) - expressed by the quantity $(\mathrm{kg})$ of generated conversion $\mathrm{SO}_{2}$ to a kilogram of transformed waste [ $\mathrm{kg}$ of $\mathrm{SO}_{2 \text {-eq }} / \mathrm{kg}$ of waste],

- EP (Eutrophication Potential) - expressed by the quantity $(\mathrm{kg})$ of generated conversion $\mathrm{PO}_{4}$ to a kilogram of transformed waste [ $\mathrm{kg}$ of $\mathrm{PO}_{4-\mathrm{eq}} / \mathrm{kg}$ of waste], 
- TOFP (Tropospheric Ozone Formation Potential) expressed by the quantity $(\mathrm{kg})$ of generated conversion ethylene to a kilogram of transformed waste $[\mathrm{kg}$ of ethylene / $\mathrm{kg}$ of waste],

- PFP (Particle Formation Potential) - expressed by the quantity $(\mathrm{kg})$ of generated conversion $\mathrm{PM}_{10}$ to a kilogram of transformed waste $\left[\mathrm{kg}\right.$ of $\mathrm{PM}_{10-e q} / \mathrm{kg}$ of waste],

- CRP (Carcinogenic Risk Potential) - (basically carcinogenicity) expressed by the quantity $(\mathrm{kg})$ of generated conversion As to a kilogram of transformed waste [ $\mathrm{kg}$ of As-eq $/ \mathrm{kg}$ of waste],

- HTTP (Human Toxicity Potential) - expressed by the quantity $(\mathrm{kg})$ of generated conversion $\mathrm{Pb}$ to $\mathrm{a}$ kilogram of transformed waste [ $\mathrm{kg}$ of $\mathrm{Pb}$-eq $/ \mathrm{kg}$ of waste],

- POCP (Photochemical Ozone Creation Potential,)

- ADP (Abiotic Depletion Potential) - expressed by the quantity $(\mathrm{kg})$ of generated conversion $\mathrm{Sb}$ to a kilogram of transformed waste [ $\mathrm{kg}$ of $\mathrm{Sb}$-eq $/ \mathrm{kg}$ of waste],

As one can see in the picture placed below (figure 2) the influence on the natural environment is presented in two variants. Namely, in one graph both the environmental burden and environmental benefit caused by the application of particular technologies of waste treatment are compared.

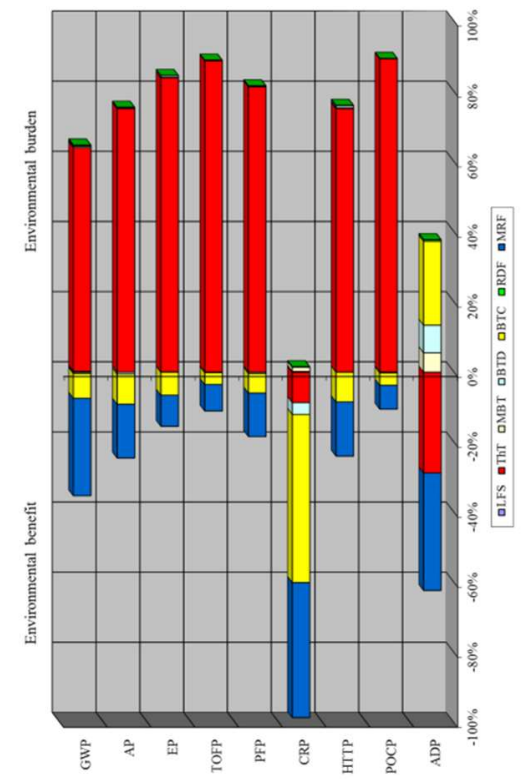

where:

GWP - Global Warming Potential, AP - Acidification Potential, EP - Eutrophication Potential, TOFP Tropospheric Ozone Formation Potential, PFP - Particle formation potential, CRP - Carcinogenic Risk Potential, HTTP - Human Toxicity Potential, POCP - Photochemical Ozone Creation Potential, ADP - Abiotic Depletion Potential, LFS - Landfill Site, ThT - Thermal Treatment, MBT Mechanical-Biological Treatment, BTD - Anaerobic Biological Treatment, BTC - Aerobic Biological Treatment, RDF - "dirty" Mechanical Recycling Facility, MRF - "clean" Mechanical recycling Facility,

Fig. 2. The influence of individual methods of waste recovery and disposal on the environment. Source: [7]

While looking at the graph it is not difficult to note that the biggest environmental burden is caused by the waste incineration (marked in red), while the greatest environmental benefit is brought by the application of recovery methods (recycling) - colour dark blue - and also by biological aerobic waste treatment (colour yellow).

\subsection{Economic criteria}

In the economic balance both direct economic and ecological effects of an undertaking should be taken into consideration. Because of difficulties in determining the value of obtained ecological effect, ecological issues are often entered into the economic efficiency balance through the estimation of ecological losses, that is economic consequences of the environment degradation, excluding values of obtained ecological advantages [8].

In the literature [9-13] ecological losses are defined as any negative effects and phenomena caused by the environment pollution which lower substantially the level of life quality. The losses are of economic nature (measured with the aid of money) and social nature (immeasurable or difficult to measure and connected mainly with work and leisure conditions) [10].

Determining real values of economic and ecological losses is extremely problematic due to existing methodical difficulties. The difficulties arise from the complexity of determining losses in particular components of the natural environment, especially their productivity in natural units and transition from the physical recognition of losses to their real meaning (money) [11]. An additional complication in this area is the fact that total interaction of greater number of various pollutants causes significant growth of threat to human health and the environment in comparison with influence of only one type of harmful substance (synergy effect) [12].

The fundamental problem of each taken economic initiative, related with investments, is the evaluation of its efficiency which constitutes motives for the execution or discontinuation. In case of possessing opportunities of the utilization of resources for various ventures, one should choose the most effective ones. And in case of making the decision on the execution of particular investment - minimize the incurred expenditure - either at the time of organizing an object or during facility's operation.

The essential condition for the success of all actions of the environment protection is creating economic bases. Construction of a system of new pro-ecologic mechanisms and economic instruments should enhance the role of sectors - that benefit from the access to environmental goods - in financing corrective ventures and influence the development of sector of services and environmental products and sphere of recreational services - stimulating the innovation in enterprises.

System of economic instruments should especially reward the prevention of waste generation at the source, raw material recovery, re-use of waste - including the energy contained in it, final disposal of unused waste in an environmentally safe way, decrease in energy and material consumption in production (application of cleaner technologies), use of alternative renewable 
energy sources, practical application of results of the analysis of full 'lifecycle' of product, production, transport, packaging, use, probable re-use and disposal $[5,14]$. Yet, one should note that so far no methodology of how to estimate the balances was developed [8].

Thanks to opportunities which are created by conducting a sozo-economical assessment it is possible to link economic and ecological efficiency and to calculate the economic and ecological effectiveness. As the outcome of execution of such balance it is possible to assess ecological losses caused by a particular economic activity taking into consideration immeasurable losses understood in a wider sense and to estimate social and economic benefits gained as a result of economic activity continuation $[8,10,12]$. In other words it is a balance of ecological losses and social and economic advantages caused by a particular economic activity.

In figure 3 costs related with processing of waste on particular installations are presented, in division by social costs as well as saved social costs (social saving cost).

The waste management generates three groups of costs:

1. Social costs - these are first of all labour costs, incurred operational and maintenance costs of a given facility.

2. Environmental expenses - direct expenses and costs incurred by the environment as a result of elimination of a given factor.

3. And the last group of costs - social cost saving (related with energy and matter recycling) which one should treat as the income.

According to the data presented in the figure 3 we can state that the application of technology of 'clean' mechanical recycling (MRF) brings the biggest social benefits - amounting to 429,9 PLN/Mg. Other technologies the use of which brings measurable social advantages are as follows:

- aerobic-biological methods (BTC) - advantage of 129,1 PLN/Mg,

- mechanical-biological methods (MBT) - benefit of 95,9 PLN/Mg,

— so-called 'dirty' mechanical recycling (RDF) advantage of 50,5 PLN/Mg,

- anaerobic-biological methods (BDT) - benefit of 25,4 PLN/Mg.

Methods the application of which brings more social costs than benefits are: thermal methods (THT) - social cost equal to 199,6 PLN/Mg and storage (LFS) - 531,1 PLN/Mg.

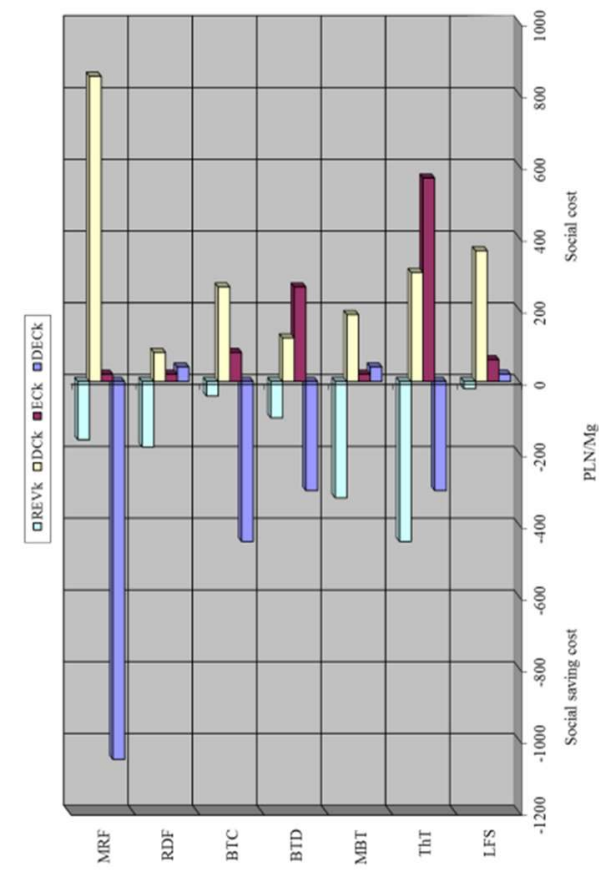

where:

MRF - "clean" Mechanical recycling Facility, RDF - "dirty" Mechanical Recycling Facility, BTC - Aerobic Biological Treatment, BTD - Anaerobic Biological Treatment; MBT Mechanical-Biological Treatment, ThT - Thermal Treatment, LFS - Landfill Site, REVk - Social saving Costs, DCk Disposal Costs, ECk - Environmental Costs, DECk Displaced Environmental Costs,

The given values have been calculated from the original data (stated in Euro for the year 2005) with the use of GDP Deflator (annual percent) 1991-2020 (The United Nations Industrial Commodity Statistics Database). The year 2019 has been adopted as the reference year.

The value has been calculated from the original data in Euro with the NBP (National Bank of Poland) average exchange rate (year 2019) at 4,3 PLN/EUR

Fig. 3. Costs (PLN/Mg) incurred as result of waste processing with use of various methods of recovery and disposal Source: own research on the basis of [7]

Methods of economic valuation often have influence on the public process of decision making. The advantage of those methods is determining values in monetary units which makes that values of resources different types are comparable. In other words, they are expressed in the same units. The interaction of various installations of waste processing causes negative effects to the environment in which entities reside that are vulnerable to the negative effect to a various degree. This is why it is worth investing in such technologies of hazardous waste disposal which will allow to eliminate or significantly reduce the storage of waste. And that will lead to the improvement of status of the natural environment to a considerable extent. 


\subsection{Technological criteria}

Recovery of raw materials from waste, waste disposal and storage require expensive installations, equipment and proper technologies. It involves costs related with waste transportation and reloading as well as investment and operating costs for facilities [15]. One should not also forget about burden to the environment through byproducts such as sewage, waste gases and others $[5,14$, 16-18].

In table 2 unit costs of hazardous waste treatment in Poland are presented.

Table 2. Unit costs of processes of recovery/disposal of hazardous waste, Source: [5].

\begin{tabular}{|l|c|}
\hline $\begin{array}{l}\text { Method of } \\
\text { recovery/disposal }\end{array}$ & $\begin{array}{c}\text { Cost of } \\
\text { recovery/disposal } \\
\text { PLN/Mg }\end{array}$ \\
\hline Thermal disposal & 3050 \\
\hline $\begin{array}{l}\text { Immobilization in } \\
\text { concrete }\end{array}$ & 1220 \\
\hline Individual processes & 12200 \\
\hline Separation of emulsion & 366 \\
\hline $\begin{array}{l}\text { Utilization in industrial } \\
\text { processes }\end{array}$ & 488 \\
\hline $\begin{array}{l}\text { Chemical sewage } \\
\text { treatment }\end{array}$ & 976 \\
\hline $\begin{array}{l}\text { Physico-chemical } \\
\text { treatment }\end{array}$ & 2440 \\
\hline $\begin{array}{l}\text { Disposal of waste from } \\
\text { explosives }\end{array}$ & 976 \\
\hline $\begin{array}{l}\text { Storage until development } \\
\text { of technologies }\end{array}$ & 610 \\
\hline $\begin{array}{l}\text { Storage in landfills for } \\
\text { hazardous waste/secure } \\
\text { chemical landfill }\end{array}$ & $345,2-2761,3$ \\
\hline Storage of asbestos & $170,3-732$ \\
\hline Recovery of mercury & 480 \\
\hline Recovery of solvents & 3050 \\
\hline Recovery of metals & 610 \\
\hline
\end{tabular}

\section{Summary}

Economic and social processes which occurred for the past decades (in many cases they still last) caused many losses in the environment. The most significant processes are the industrialization and urbanization. They intensified the negative transformation of all components of the environment which is demonstrated most in case of the water, air and contamination with waste.

The waste is not only an attribute of contemporary life, but also a manifestation of imperfection in management of material substance in the environment. The rational waste management allows both for the improvement of the environment condition and the increase in material and raw material resources. Growing prices of raw materials and energy in long periods and the critical condition of the environment clearly show that times of carefree attitude to raw material resources and natural environment have irrevocably gone. The depletion of resources and the strict requirement of environment protection must be taken into consideration as the decisive factor in decisions taken by manufacturers and consumers of goods. It is a natural thing that one seeks to recover many raw materials from waste more and more frequently.

Organizing comprehensive hazardous waste management causes a decrease in number of facilities in which such waste is disposed. The desired result of such measure is the limitation of quantity of potential sources of environment contamination and bigger economic effects (than in case of individual enterprises). One cannot also omit the fact that the comprehensive hazardous waste management has a positive impact on the choice of optimal technology of disposal of hazardous waste and this in turn is related with enabling the introduction of modern technologies, full application of technological operations, increase in work efficiency, obtaining lower operating costs and ensuring the environment protection at a proper level.

The work is financed within the frames of research subsidy no 16.16.210.476 at the Faculty of Energy and Fuels, AGH University of Science and Technology.

\section{References}

1. Eurostat (2021)

http://ec.europa.eu/eurostat/web/environment/wast e/database (17.04.2021)

2. Regulation of the Minister for the Environment as of the $9^{\text {th }}$ of December 2014 concerning the catalogue of waste (Journal of Laws 2014, item 1923)

3. Statistics Poland - Główny Urząd Statystyczny http://swaid.stat.gov.pl/StanOchronaSrodowiska_d ashboards/Raporty_predefiniowane/RAP_DBD_S ROD_6.aspx (17.04.2021)

4. J. Pyssa J, IOP Conference Series: Earth and Environmental Science, 214, 012022, (2019)

5. J. Pyssa, E3S Web of Conferences, 19, 02021, (2017)

6. Act of environmental law (Journal of Laws 2001, No 62, item 627) of the $27^{\text {th }}$ of April 2001 (uniform text Journal of Laws 2020, item 1219)

7. E.M. Oropeza, SUWAMAS, A Decision Support Model For Sustainable Waste Management System, Dortmund (doctoral thesis) (2006) https://eldorado.tudortmund.de/handle/2003/22997 (17.04.2021)

8. J. Pyssa, Przemysł chemiczny 89, 7, (2010)

9. A. Bernaciak, W.M. Gaczek, Economic aspects of environmental protection, Publisher of University of Economics in Poznan, Poznań (2001)

10. A. Hołuj, Folia Oeconomica Bocheniensia, 4, (2006)

11. B. Filipiak, M. Cieciura, H. Czaja-Cieszyńska, A. Niewęgłowski, P. Szczypa, Cost account in the environmental protection, CeDeWu Publishing House, Warszawa (2010) (in Polish) 
12. A. Augusewicz, T. Breńko, A. Kozłowska, R. Miłoszewski, B. Karolinczak, A. WernerJuszczuk, P. Winiarek, Civil and Environmental Engineering/Budownictwo i inżynieria środowiska, 3, 1, (2012)

13. A. Becia, S. Czaja, A. Zielińska, Cost And Benefit Analysis In Valuation Of The Natural

Environment, Difin Publisher, Warsaw (2012) (in Polish)

14. J. Wu, Y. Guo, C.H. Li, H. Qi, Journal of Cleaner Production, 149, (2017)

15. M.N. Rao, R. Sultana, S.H. Kota, Solid and Hazardous Waste Management. Science and Technology, Butterworth-Heinemann, (2017)

16. E. Adar, E.K. Delice, T. Adar, Int. J. Environ. Sci. Technol. (2021). https://doi.org/10.1007/s13762021-03511-y

17. O. Sheveleva, E. Slesarenko, N. Kudrevatykh, M. Kumaneeva, E3S Web of Conferences 174, 04008 (2020)

18. M. Smol, P. Marcinek, E. Koda, Energies, 14, 2219 (2021) 